\title{
Performance of Aptima E6/E7 mRNA HPV assays on fine needle aspirates from cervical lymph nodes of patients with metastatic oropharyngeal squamous cell carcinoma
}

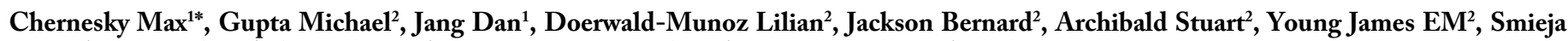
Marek $^{1}$, Lytwyn Alice ${ }^{1}$, Arias Manuel ${ }^{1}$, Ecobichon-Morris Anne ${ }^{1}$ and Hyrcza Martin ${ }^{1}$

${ }^{1}$ St. Joseph's Healthcare Hamilton/ McMaster University, 50 Charlton Avenue East, Hamilton, ON, Canada

2Juravinski Hospital Head \& Neck Clinic, 699 Concession St, Hamilton, ON, Canada

\begin{abstract}
Objectives: Using commercial assays for high-risk (HR) HPV E6/E7 mRNA we sought to determine the accuracy of testing fine needle aspirates (FNA) of neck cervical lymph nodes and tumor tissue from patients with metastatic oropharyngeal squamous cell carcinomas (OPSCC).

Materials and Methods: Tumor tissue which was stained for p16 antigens and FNA from patients with OPSCC in tonsils ( $\mathrm{n}=40)$, base of tongue ( $\mathrm{n}=30)$ and other sites of the oropharynx $(\mathrm{n}=6)$ were tested for HR HPV E6/E7 mRNA using Aptima assays (Hologic). These samples were also tested for HR HPV DNA using cobas 4800 (Roche) and/or Cervista (Hologic) assays. FNA sample adequacy was determined by qPCR for $\bigotimes$-actin.

Results: HR HPV mRNA and DNA were detected in $68.4 \%$ and $71.4 \%$ of FNA samples, respectively, and $96.4 \%$ were HPV genotype $16.81 \%$ of tumor tissue samples were positive for p16 staining. 82.2\% of FNA samples from patients with p16 positive tumors were positive for HPV mRNA compared to $82.4 \%$ for HPV DNA. Agreement between FNA testing for HPV and p16 stained tumors was $84.2 \%(\mathrm{k}=0.59)$ for mRNA compared to $81.4 \%$ ( $\mathrm{k}=0.49)$ for DNA. For all specimens, agreement was $94.3 \%(\mathrm{k}=0.86)$ between Aptima mRNA and cobas DNA and $94.3 \%(\mathrm{k}=0.77)$ between the cobas and Cervista DNA assays. A subset of 35 paraffinembedded primary tumors were extracted and tested in the HPV assays and an equal number of cases were positive for mRNA, DNA and p16. The FNA adequacy rate was $92 \%$.
\end{abstract}

Conclusion: The excellent performance of the Aptima HPV E6/E7 mRNA assays indicate that commercial tests should be validated and used for these purposes.

\section{Background}

Head and neck squamous cell carcinomas (HNSCC) may be associated with high-risk human papillomavirus (HR-HPV), predominantly genotype 16 and mainly present in oropharyngeal squamous cell carcinomas (OPSCC) involving the tonsils, base of tongue (BOT) and other sites [1]. During HR-HPV oncogenesis, transcription of viral oncoproteins E6 and E7 interfere with p53 and retinoblastoma ( $\mathrm{pRb}$ ) tumor suppressor pathways, a consequence of which includes the overexpression of p16 antigen [2]. The p16 immunohistochemical (IHC) test has been useful as a surrogate marker for transcriptionallyactive HPV [3,4]. HPV can be detected in SCC tissue using HPV in-situ hybridization (HPV-ISH), and commercial ISH assays have been used for detecting HPV DNA (DNA ISH) or mRNA (RNA ISH) [5]. RNA ISH appears to correlate more accurately with transcriptionally active HR-HPV [6-8]. Laboratory-developed tests (LDT) for HPV DNA and mRNA using PCR technology have been used on fresh, frozen and formalin-fixed paraffin-embedded (FFPE) tumor tissue [3].

Some patients have metastatic spread of their HNSCC to regional lymph nodes which may be the first clinical manifestation of disease [9]. Fine needle aspiration (FNA) of cervical lymph nodes has become a convenient sample for cytological and virological testing. Previous studies demonstrated that fixed and embedded FNA tested by p16 IHC and/or HPV-ISH (DNA) enabled differentiation of OPSCC from non-OPSCC tumors [10-15]. Both LDT's and commercial assays for the detection of HR-HPV DNA have been used on FNA samples. An LDT PCR has used MY09/11 primers [16], whereas the commercial DNA assays used Hybrid Capture (HC2, Qiagen) [17,18]; Cervista (Hologic) [19-21]; cobas PCR (Roche) [22,23] and the PCR genotyping INNO-LIPA Extra System Kit (Innogenetics) [24]. Accuracy of HPV testing of FNA compared results to the presence of p16 and HR HPV or HPV16 DNA in tumors using ISH. Commercial non-ISH DNA HPV assays are approved for use on genital samples for the diagnosis of cervical cancer and cancer precursors, but not for FNA or tumor tissue. The advantages and disadvantages of HPV and/or surrogate marker detection for HNSCC diagnosis have been reviewed [5,2528] and research approaches to the clinical diagnosis of HPV-related OPSCC have been proposed [29]. These excellent reviews agree that the goal should be to diagnose OPSCC driven by transcriptionally-active

Correspondence to: Max Chernesky, PhD, St. Joseph's Healthcare, 50 Charlton Avenue E, Hamilton, ON, Canada, Tel: (905) 522-1155 x35012; Fax: (905) 5216083; E-mail: chernesk@mcmaster.ca

Key words: head and neck cancer, HPV, E6/E7 mRNA assays, Fine needle aspirates, FNA specimen adequacy, p16 immunohistochemistry, tonsillar cancers, base of tongue cancers, oropharyngeal squamous cell carcinoma, HRHPV genotype 16, nucleic acid extraction of FFPE tumors

Received: October 18, 2017; Accepted: November 07, 2017; Published: November 10, 2017 
Max C (2017) Performance of Aptima E6/E7 mRNA HPV assays on fine needle aspirates from cervical lymph nodes of patients with metastatic oropharyngeal squamous cell carcinoma

HPV by testing tumor tissue or FNA with relevant assays. The tests should be sensitive and specific, with appropriate time to results, of low complexity and cost, and easily incorporated into a diagnostic setting.

The Aptima HPV assay detects E6 and E7 mRNA from 14 HRHPV genotypes, and its companion genotyping test (Aptima 16 18/45) detects E6/E7 mRNA from HPV 16 or a combination of HPV 18 and 45 genotypes. Both are transcription-mediated amplification (TMA) assays approved for use on genital samples for the diagnosis of cervical pre-cancer and cancer $[30,31]$. The objective of the current study was to enroll patients with OPSCC attending a regional referral clinic to test their FNA with Aptima HPV mRNA assays, and to compare the results to HPV DNA testing of FNA and p16 staining of tumors, which were extracted to measure HPV DNA and mRNA with the same commercial assays.

\section{Materials and methods}

\section{Specimens and cases}

We enrolled 69 males and 7 females with OPSCC, age range 4080 (median 57 years). A total of 40 had primary tonsillar tumors, 30 base of tongue (BOT) tumors and 6 had tumors at other oropharyngeal primary sites ( 1 vallecular, 1 pharyngeal wall and 4 soft palate). Patients with oropharyngeal squamous cell carcinoma with regional metastatic spread to cervical lymph nodes were enrolled from July 2012 to July 2015 at the Juravinski Cancer Center Head and Neck Clinic (Hamilton, Ontario, Canada). Each participant had the study explained and signed an informed consent approved by the Hamilton Integrated Research Ethics Board (HIREB). Primary cancer tumors were identified and p16 IHC was performed on tumor tissues using a commercial kit (CINtec Histology Kit, Roche MTM Laboratories, Mannheim, Germany). Tumors were considered positive for $\mathrm{p} 16$ if $\geq 70 \%$ of tumor cells demonstrated strong diffuse nuclear and cytoplasmic staining [26]. All p16-stained slides were blinded and reread by a study pathologist coinvestigator.

FNA of the cervical lymph node was collected by a Head and Neck surgeon for HPV testing using several passes with a syringe and 22 -gauge needle. The syringe was emptied directly into a vial containing $4 \mathrm{ml}$ of PreservCyt (Hologic) liquid-based media and an additional 1 $\mathrm{ml}$ was added when received in the laboratory. FNA samples were not tested by p16 IHC.

\section{Aptima HPV testing for mRNA}

Within 24-48 hours of receipt in the laboratory, $1 \mathrm{ml}$ of each FNA sample was transferred to an Aptima tube containing specimen transport media (STM), and was tested with the Aptima HPV assay on TIGRIS DTS or Panther systems according to the manufacturer's instructions. The assay contains positive and negative controls. Assay results were interpreted based on the signal-to-cutoff ratio (S/CO) and values $\geq 0.5$ were considered positive. Specimens positive by AHPV testing were genotyped in the Aptima HPV 16 18/45 assay which contains positive and negative calibrators.

\section{cobas PCR DNA testing}

One $\mathrm{ml}$ of the FNA sample was transferred into an empty $13 \mathrm{ml}$ Sarstedt screw-capped round bottomed tube for cobas HPV testing on the cobas 4800 (Roche). Testing was performed at the Newfoundland and Labrador Public Health Laboratory in St. John's, NL. The cobas assay identified genotypes 16 and 18, while simultaneously detecting 12 other HR-HPV genotypes 31, 33, 35, 39, 45, 51, 52, 56, 58, 59, 66 and 68 collectively. Positive and negative controls are performed in the assay.
The cobas 4800 software interpreted for each sample the outcomes and reported the results as negative, HPV 16, HPV 18 or other HR-HPV.

\section{Cervista HPV DNA assays}

Cervista HPV 16/18 and Cervista HPV-HR assays (Hologic, Madison, WI, USA) were conducted according to the manufacturer's instructions. One $\mathrm{ml}$ of an FNA sample from 35 patients were tested for HR HPV by both Cervista and cobas assays. The Cervista assays use Invader Chemistry signal amplification for the detection of specific nucleic acid sequences. The assay contains positive and negative controls. Sample DNA was extracted using a Genfind DNA Extraction Kit (Hologic). For the HR-HPV test 14 genotypes were detected by 3 separate reactions for (a) genotypes 51, 56 and 66; (b) genotypes 18, 39, $45,59,68$ and (c) genotypes 16, 31, 33, 35, 52 and 58. For the Cervista HPV 16/18 assay, 2 oligonucleotide mixtures were used that contained probes specific for the L1, E6 and E7 genomic regions of genotypes 16 or 18. A fold over zero (FOZ) ratio, which is a measurement of the fluorescent signal of the sample divided by a no target control, greater than 1.525 was considered positive.

\section{$\beta$-actin specimen adequacy assay}

FNA samples from 9 patients who had p16-positive tumors but HPV-negative FNA samples, as well as 3 positive controls, were tested for $\beta$-actin DNA as a quantitative internal control for the amount of specimen collected in each sample type. DNA from $250 \mathrm{ul}$ of the FNA samples in PreservCyt were extracted with Qiagen MinElute spin columns using a modified protocol from the AmpliLute Liquid Media Extraction Kit (Roche, Pleasanton, CA, USA), followed by qPCR using previously published $\beta$-actin primers [32].

\section{Processing of tumor tissue for HPV testing}

FFPE blocks of tumor tissue from 35 patients (22 tonsillar, 11 base of tongue and 2 with soft palate tumors) were available to be retrieved and processed at the end of the study. Following strict procedures, the use of a new disposable blade was implemented, and a thorough wipe down of the microtome area with RNAseZap/DNAZap decontamination solutions between blocks was performed. Non-tissue paraffin blocks were used as a sentinel for contamination. Four curls of 25 microns were cut and placed into a $15 \mathrm{ml}$ conical tube. The curls were incubated in $2.9 \mathrm{ml}$ of Aptima STM for 30 minutes at $60^{\circ} \mathrm{C}$ with intermittent shaking to partially dissolve the paraffin wax, followed by 5 -minute incubation on ice. The STM was removed from each tube and pipetted into an empty Aptima STM tube [33]. Samples were tested according to the HPV kit package inserts and p16 positive and negative samples were included as external controls.

\section{Statistical analysis}

Overall agreement between assay results and specimen types, and chance-adjusted agreement (kappa), were calculated.

\section{Results}

HPV mRNA and DNA were detected in $68.4 \%(52 / 76)$ and $71.4 \%(50 / 70)$ of FNA samples respectively, and $82.2 \%(51 / 62)$ of FNA samples from the patients with p16 positive tumors were positive for mRNA compared to $82.4 \%(47 / 57)$ for DNA by cobas testing (Table 1-all 76 patients).

Supplementary Table 1 summarizes the results of testing FNA samples for the presence of HR-HPV mRNA and DNA from 40 patients with primary tonsillar tumors which were tested for p16 and HR- 
Max C (2017) Performance of Aptima E6/E7 mRNA HPV assays on fine needle aspirates from cervical lymph nodes of patients with metastatic oropharyngeal squamous cell carcinoma

Table 1. Positive, negative and overall percent agreements (PPA, NPA, OA) for comparisons of testing of Fine Needle Aspirates (FNA) with APTIMA HPV mRNA and cobas DNA to tumor testing (p16, HPV mRNA and DNA).

\begin{tabular}{|c|c|c|c|c|c|c|c|c|c|c|c|c|c|}
\hline & \multirow{2}{*}{\multicolumn{4}{|c|}{$\begin{array}{c}\text { All Patients }(\mathrm{n}=76) \\
\text { p16 }\end{array}$}} & \multicolumn{9}{|c|}{ Patients with tumor p16 IHC and HPV testing ( $\mathrm{n}=35$ ) } \\
\hline & & & & & \multicolumn{3}{|c|}{ p16 } & \multicolumn{3}{|c|}{ Tumor mRNA } & \multicolumn{3}{|c|}{ Tumor DNA } \\
\hline & & + & - & Total & + & - & Total & + & - & Total & + & - & Total \\
\hline & + & 51 & 1 & 52 & 22 & 1 & 23 & 22 & 1 & 23 & 22 & 1 & 23 \\
\hline FNA & - & 11 & 13 & 24 & 7 & 5 & 12 & 7 & 5 & 12 & 7 & 5 & 12 \\
\hline \multirow[t]{6}{*}{ Aptima HPV mRNA } & Total & 62 & 14 & 76 & 29 & 6 & 35 & 29 & 6 & 35 & 29 & 6 & 35 \\
\hline & & \multicolumn{3}{|c|}{$\mathrm{PPA}=81.0$} & \multicolumn{3}{|c|}{$\mathrm{PPA}=73.3$} & \multicolumn{3}{|c|}{$\mathrm{PPA}=73.3$} & \multicolumn{3}{|c|}{$\mathrm{PPA}=73.3$} \\
\hline & & \multicolumn{3}{|c|}{$\mathrm{NPA}=92.9$} & \multicolumn{3}{|c|}{$\mathrm{NPA}=83.3$} & \multicolumn{3}{|c|}{$\mathrm{NPA}=83.3$} & \multicolumn{3}{|c|}{$\mathrm{NPA}=83.3$} \\
\hline & & \multicolumn{3}{|c|}{$\mathrm{OA}=84.2 ; \mathrm{k}=0.59$} & \multicolumn{3}{|c|}{$\mathrm{OA}=77.1 ; \mathrm{k}=0.42$} & \multicolumn{3}{|c|}{$\mathrm{OA}=77.1 ; \mathrm{k}=0.42$} & \multicolumn{3}{|c|}{$\mathrm{OA}=77.1 ; \mathrm{k}=0.42$} \\
\hline & & + & - & Total & + & - & Total & + & - & Total & + & - & Total \\
\hline & + & 47 & 3 & 50 & 22 & 2 & 24 & 22 & 2 & 24 & 22 & 2 & 24 \\
\hline FNA & - & 10 & 10 & 20 & 6 & 4 & 10 & 6 & 4 & 10 & 6 & 4 & 10 \\
\hline \multirow[t]{4}{*}{ cobas HPV DNA } & Total & 57 & 13 & 70 & 28 & 6 & 34 & 28 & 6 & 34 & 28 & 6 & 34 \\
\hline & & \multicolumn{3}{|c|}{$\mathrm{PPA}=78.3$} & \multicolumn{3}{|c|}{$\mathrm{PPA}=73.3$} & \multicolumn{3}{|c|}{$\mathrm{PPA}=73.3$} & \multicolumn{3}{|c|}{$\mathrm{PPA}=73.3$} \\
\hline & & \multicolumn{3}{|c|}{$\mathrm{NPA}=76.9$} & \multicolumn{3}{|c|}{$\mathrm{NPA}=66.6$} & \multicolumn{3}{|c|}{$\mathrm{NPA}=66.6$} & \multicolumn{3}{|c|}{$\mathrm{NPA}=66.6$} \\
\hline & & \multicolumn{3}{|c|}{$\mathrm{OA}=81.4 ; \mathrm{k}=0.49$} & \multicolumn{3}{|c|}{$\mathrm{OA}=76.5 ; \mathrm{k}=0.36$} & \multicolumn{3}{|c|}{$\mathrm{OA}=76.5 ; \mathrm{k}=0.36$} & \multicolumn{3}{|c|}{$\mathrm{OA}=76.5 ; \mathrm{k}=0.36$} \\
\hline
\end{tabular}

HPV nucleic acids. Testing the FNA samples identified $67.5 \%(27 / 40)$ positive for HR HPV mRNA and 72.2\% (26/36) positive for HR HPV DNA. The tumor p16 positivity rate was $77.5 \%(31 / 40)$. Testing of FNA from the 31 patients with p16-positive tumors with the Aptima HPV mRNA assay detected $83.9 \%(26 / 31)$ and the cobas DNA test detected $85.7 \%(24 / 28)$. For the 9 patients with p16-negative tumors, FNA testing detected 1 as positive for mRNA and 2 for DNA. FNA samples from 3 patients with p16-positive tumors were negative for both HPV nucleic acids (patients 8, 58, 38). The Aptima HPV assay identified 27 FNA samples as HPV positive (26 samples were identified further as HPV 16 and one sample as other than types 16,18 or 45 positive). The cobas HPV assay identified 26 FNA samples as genotype 16 and one sample as other than types 16 or 18 .

Supplementary Table 2 summarizes testing of the 30 patients with BOT tumors. Testing FNA samples identified $73.3 \%(22 / 30)$ with mRNA and $75 \%(21 / 28)$ with DNA. The tumor p16 positivity rate was $93.3 \%(28 / 30)$. FNA positivity rates for the 28 BOT patients with p16-positive tumors were $78.6 \%(22 / 28)$ for mRNA and $77.1 \%$ (20/26) for DNA. Both the mRNA Aptima assay and the DNA cobas test performed on FNA were negative in 6 patients $(7,39,72,88,25$, 82) who had p16-positive tumors. Two patients at the bottom of the table with p16-negative tumors had a negative mRNA result and 1 had a positive DNA test on FNA. As in the patients with tonsillar tumors, the majority of BOT cases were genotype 16 infections.

Supplementary Table 3 shows the results of testing the FNA from patients with other primary tumor sites. Three (50\%) had p16-positive tumors and both HPV mRNA and DNA were detected in FNA samples. Three patients with soft palate tumors had p16-negative tumor tissue and their FNA samples were negative for HPV mRNA and DNA.

We were able to retrieve FFPE tumor blocks (20 tonsillar, 13 BOT and 2 others) from 35 of the 76 enrolled patients and they were processed for detection of extracted HPV mRNA and DNA. The results were almost identical for HPV mRNA or DNA and p16 IHC testing. Both the Aptima HPV mRNA and the cobas HPV DNA test identified $96.5 \%(28 / 29)$ of the tumors that were p16 IHC positive (Table 2). The HPV assays were positive on a p16-negative tumor from patient 91 and were negative on a tumor which was p16-positive (patient 35). Comparing the Aptima HPV and cobas HPV assays performed on FNA, the Aptima mRNA assay detected $75.9 \%$ (22/29) compared to the cobas DNA test which detected $78.6 \%(22 / 28)$ of patients with p16-positive tumors. Aptima mRNA and cobas DNA were found in the FNA from patient 91 with a tumor negative by staining p16 but positive for HPV mRNA and DNA. Patient 63 had a positive cobas HPV DNA test of FNA with all other testing negative.

Table 1 compares agreements between HPV testing of FNA for the larger group of p16-tested OPSCC tumors $(n=76)$, and in the smaller group $(\mathrm{n}=35)$ tested by $\mathrm{p} 16$ and with Aptima mRNA and cobas DNA assays. FNA testing with the mRNA assay and p16 testing of tumors had a percent overall agreement of $84.2(\mathrm{k}=0.59)$. Agreement of the cobas HPV DNA results for testing FNA showed a slightly lower percent overall agreement of $81.4(\mathrm{k}=0.49)$ with p16 tested tumors. Similar calculations for the smaller group of 35 patients with tumor tissue available for both p16 staining and HPV nucleic acid testing showed slightly lower agreement values $77.1(\mathrm{k}=0.42)$ and were identical for the Aptima HPV mRNA assay and the cobas HPV DNA test on FNA with the 3 tumor measurements (p16, mRNA, DNA) individually or together. Negative percent agreement (NPA) with the 3 tumor measurements was $83.3 \%$ for the FNA tested for mRNA compared to $66.6 \%$ for cobas DNA.

Table 3 shows agreements between the mRNA Aptima assay and the cobas DNA test, and between the cobas and Cervista DNA tests on FNA samples. Both comparisons showed strong overall agreement: 94.3\% $(\mathrm{k}=0.86)$ and $94.3 \%(\mathrm{k}=0.77)$, respectively.

Assuming that FNA samples yielding a positive result in the Aptima HPV mRNA assay or in the cobas HPV DNA test were adequate specimens, FNA samples which were HPV negative from 9 patients with p16-positive tumors were retrieved and examined for the presence of $\beta$-actin as an indicator of nucleic acid adequacy. Patient 72 (Supplementary Table 2) qualified but there was insufficient volume of FNA for processing. As shown in Table 4, control patients 86, 87 and 90 at the top of the table had both HPV mRNA and DNA in FNA, and contained between 5.37-7.09 log copies/ml of $\beta$-actin. Patients 88,8 and 58 with HPV-negative FNA results were judged to be adequate because they contained 5.13 to $6.91 \mathrm{log}$ copies/ $\mathrm{ml}$ of $\beta$-actin. In contrast, 6 of the FNA samples (patients 7, 25, 39, 82, 38 and 56) had lower $\beta$-actin levels, ranging from 2.65-4.83 log copies/ml. FNA samples from patients with low $\beta$-actin levels (7, 25 and 39) also had low genomic DNA in the Cervista assay and a fourth (patient 56) was also invalid in the cobas DNA test, which is suggestive of inadequate amounts of DNA for HPV testing. 
Max C (2017) Performance of Aptima E6/E7 mRNA HPV assays on fine needle aspirates from cervical lymph nodes of patients with metastatic oropharyngeal squamous cell carcinoma

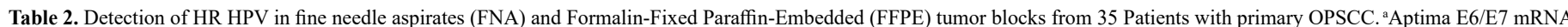
assays; ${ }^{b}$ cobas $4800 \mathrm{HPV}$ DNA assay; ${ }^{\mathrm{c}} 16$ immunohistochemical stain of formalin-fixed paraffin-embedded tissue; ${ }^{\mathrm{d}} \mathrm{HPV}$ genotypes $31,33,35,39,45,51,52,56,58,59,66$ or $68 ;{ }^{\mathrm{e}} \mathrm{Non}-$ HPV 16 or $18 / 45$; ISV-Insufficient volume.

\begin{tabular}{|c|c|c|c|c|c|}
\hline \multirow[b]{2}{*}{ Patient ID } & \multicolumn{2}{|c|}{ FNA } & \multicolumn{3}{|c|}{ Tumor Tissue } \\
\hline & $\mathrm{mRNA}^{\mathrm{a}}$ & DNA $^{b}$ & $\mathrm{p} 16^{\mathrm{c}}$ & $\mathrm{mRNA}^{\mathrm{a}}$ & $\mathrm{DNA}^{\mathrm{b}}$ \\
\hline 8 & - & - & + & + other $^{e}$ & + other $^{d}$ \\
\hline 13 & 16 & 16 & + & 16 & 16 \\
\hline 17 & 16 & 16 & + & 16 & 16 \\
\hline 18 & 16 & 16 & + & 16 & 16 \\
\hline 19 & 16 & 16 & + & 16 & 16 \\
\hline 24 & 16 & 16 & + & 16 & 16 \\
\hline 35 & 16 & 16 & + & - & - \\
\hline 37 & 16 & 16 & + & 16 & 16 \\
\hline 44 & 16 & 16 & + & 16 & 16 \\
\hline 45 & 16 & 16 & + & 16 & 16 \\
\hline 50 & 16 & 16 & + & 16 & 16 \\
\hline 51 & - & 16 & + & +other ${ }^{\mathrm{e}}$ & 16 \\
\hline 58 & - & - & + & + other $^{\mathrm{e}}$ & +other ${ }^{d}$ \\
\hline 67 & 16 & 16 & + & 16 & 16 \\
\hline 77 & 16 & 16 & + & 16 & 16 \\
\hline 78 & 16 & 16 & + & 16 & 16 \\
\hline 79 & 16 & 16 & + & 16 & 16 \\
\hline 4 & 16 & 16 & + & 16 & 16 \\
\hline 7 & - & - & + & 16 & 16 \\
\hline 32 & 16 & 16 & + & 16 & 16 \\
\hline 33 & 0.4 & + other $^{\mathrm{d}}$ & + & + other $^{\mathrm{e}}$ & $+16 /$ other $^{d}$ \\
\hline 39 & - & - & + & 16 & 16 \\
\hline 47 & 16 & 16 & + & 16 & 16 \\
\hline 52 & 16 & 16 & + & 16 & 16 \\
\hline 64 & 16 & ISV $^{\mathrm{f}}$ & + & 16 & 16 \\
\hline 72 & - & - & + & 16 & 16 \\
\hline 87 & 16 & 16 & + & 16 & 16 \\
\hline 88 & - & - & + & 16 & 16 \\
\hline 90 & 16 & 16 & + & 16 & 16 \\
\hline \multirow[t]{2}{*}{ SUBTOTALS } & $75.90 \%$ & $78.60 \%$ & $100 \%$ & $96.60 \%$ & $96.60 \%$ \\
\hline & $(22 / 29)$ & $(22 / 28)$ & $(29 / 29)$ & $(28 / 29)$ & $(28 / 29)$ \\
\hline & & & & & \\
\hline 91 & 16 & 16 & - & 16 & 16 \\
\hline 59 & - & - & - & - & - \\
\hline 85 & - & - & - & - & - \\
\hline 63 & - & 16 & - & - & - \\
\hline 6 & - & - & - & - & - \\
\hline 66 & - & - & - & - & - \\
\hline \multirow{2}{*}{ TOTALS } & $65.70 \%$ & $70.60 \%$ & $82.80 \%$ & $82.80 \%$ & $82.80 \%$ \\
\hline & $(23 / 35)$ & $(24 / 34)$ & $(29 / 35)$ & $(29 / 35)$ & $(29 / 35)$ \\
\hline
\end{tabular}

Table 3. Agreement of HPV mRNA to DNA in fine needle aspirates (FNA) of patients with oropharyngeal squamous cell carcinomas (OPSCC).

\begin{tabular}{|c|c|c|c|c|c|c|c|}
\hline & & \multicolumn{3}{|c|}{ APTIMA HPV mRNA } & \multicolumn{3}{|c|}{ Cervista HPV DNA } \\
\hline & & + & - & TOTAL & + & - & TOTAL \\
\hline Cobas & + & 47 & 3 & 50 & 29 & 0 & 29 \\
\hline \multirow[t]{5}{*}{$\begin{array}{l}\text { HPV } \\
\text { DNA }\end{array}$} & - & 1 & 19 & 20 & 2 & 4 & 6 \\
\hline & TOTAL & 48 & 22 & 70 & 31 & 4 & 35 \\
\hline & & \multicolumn{3}{|c|}{$\mathrm{PPA}=92.2$} & \multicolumn{3}{|c|}{$\mathrm{PPA}=93.5$} \\
\hline & & \multicolumn{3}{|c|}{$\mathrm{NPA}=86.4$} & \multicolumn{3}{|c|}{$\mathrm{NPA}=100$} \\
\hline & & \multicolumn{3}{|c|}{$\mathrm{OA}=94.3 ; \mathrm{k}=0.86$} & \multicolumn{3}{|c|}{$\mathrm{OA}=94.3 ; \mathrm{k}=0.77$} \\
\hline
\end{tabular}

\section{Discussion}

Using commercial assays which are approved for the detection of HR HPV in genitourinary samples for the diagnosis of cervical cancer and precancerous lesions, we prospectively tested FNA from 76 patients with OPSCC (40 tonsillar, $30 \mathrm{BOT}$ and 6 other) collected into PreservCyt media and found that $68.4 \%$ (52/76) contained HR HPV mRNA compared to $71.4 \%$ (50/70) with HR HPV DNA (Table 1), when tested without fixation within 48 hours. Like other commercial HPV tests the Aptima assay provided mRNA results the same day or within 24 hours. This is the first report on the use of the Aptima HPV 
Max C (2017) Performance of Aptima E6/E7 mRNA HPV assays on fine needle aspirates from cervical lymph nodes of patients with metastatic oropharyngeal squamous cell carcinoma

Table 4. Sample adequacy testing profiles of patients with positive IHC p16 tests of the tumour and FNA negative for HPV. aThree control patients with FNA positive for DNA and mRNA; ${ }^{\mathrm{b}} \mathrm{ND}-\mathrm{Not}$ done; ${ }^{\mathrm{c}} \mathrm{Non}-16$ or $18 / 45$ HR HPV genotypes; ${ }^{\mathrm{d}} \mathrm{HPV}$ genotypes $31,33,35,39,45,51,52,56,58,59,66$ or 68 ; ${ }^{\mathrm{e}} \mathrm{INV}-\mathrm{Invalid}$, ${ }^{\mathrm{f}} \mathrm{Base}$ of Tongue.

\begin{tabular}{|c|c|c|c|c|c|c|c|c|}
\hline \multirow{2}{*}{ Tumor Site } & \multirow{2}{*}{ Patient ID } & \multicolumn{3}{|c|}{ Tumor Tissue } & \multicolumn{4}{|c|}{ FNA } \\
\hline & & p16 & Aptima mRNA & Cobas DNA & Aptima mRNA & cobas DNA & Cervista DNA & $\beta$-actin $\log \mathbf{c} / \mathbf{m L}$ \\
\hline $\mathrm{BOT}^{\mathrm{f}}$ & $86^{a}$ & + & $\mathrm{ND}^{\mathrm{b}}$ & $\mathrm{ND}^{\mathrm{b}}$ & 16 & 16 & $\mathrm{ND}^{\mathrm{b}}$ & 6.87 \\
\hline $\mathrm{BOT}^{\mathrm{f}}$ & $87^{a}$ & + & 16 & 16 & 16 & 16 & $\mathrm{ND}^{\mathrm{b}}$ & 7.09 \\
\hline $\mathrm{BOT}^{\mathrm{f}}$ & $90^{\mathrm{a}}$ & + & 16 & 16 & 16 & 16 & $\mathrm{ND}^{\mathrm{b}}$ & 5.37 \\
\hline Tonsillar & 8 & + & Other ${ }^{\mathrm{c}}$ & Other $^{d}$ & - & - & $\mathrm{ND}^{\mathrm{b}}$ & 5.19 \\
\hline Tonsillar & 38 & + & $\mathrm{ND}^{\mathrm{b}}$ & $\mathrm{ND}^{\mathrm{b}}$ & - & - & - & 4.83 \\
\hline Tonsillar & 56 & + & $\mathrm{ND}^{\mathrm{b}}$ & $\mathrm{ND}^{\mathrm{b}}$ & - & $\mathrm{INV}^{\mathrm{e}}$ & $\mathrm{ND}^{\mathrm{b}}$ & 2.65 \\
\hline Tonsillar & 58 & + & Other ${ }^{\mathrm{c}}$ & $\mathrm{INV}^{\mathrm{e}}$ & - & - & $\mathrm{ND}^{\mathrm{b}}$ & 5.46 \\
\hline $\mathrm{BOT}^{\mathrm{f}}$ & 7 & + & 16 & 16 & - & - & $\begin{array}{c}\text { Low Genomic } \\
\text { DNA }\end{array}$ & 3.46 \\
\hline $\mathrm{BOT}^{\mathrm{f}}$ & 25 & + & $\mathrm{ND}^{\mathrm{b}}$ & $\mathrm{ND}^{\mathrm{b}}$ & - & - & $\begin{array}{c}\text { Low Genomic } \\
\text { DNA }\end{array}$ & 3.22 \\
\hline $\mathrm{BOT}^{\mathrm{f}}$ & 39 & + & 16 & 16 & - & - & $\begin{array}{c}\text { Low Genomic } \\
\text { DNA }\end{array}$ & 3.55 \\
\hline $\mathrm{BOT}^{\mathrm{f}}$ & 82 & + & $\mathrm{ND}^{\mathrm{b}}$ & $\mathrm{ND}^{\mathrm{b}}$ & - & - & $\mathrm{ND}^{\mathrm{b}}$ & 3.71 \\
\hline $\mathrm{BOT}^{\mathrm{f}}$ & 88 & + & 16 & $\mathrm{INV}^{\mathrm{e}}$ & - & - & $\mathrm{ND}^{\mathrm{b}}$ & 6.91 \\
\hline
\end{tabular}

E6/E7 mRNA assays performed on neck FNA samples. In a subset of 35 samples, a comparison to the Cervista HPV DNA signal amplification test was also conducted. The rates of HPV DNA positivity in our study confirm previous retrospective studies using similar commercial DNA assays. Kerr et al. [22] studied 36 samples (19 FNA and 17 surgical biopsies) collected into SurePath liquid Pap media from 33 patients and found $42 \%$ of samples were positive for HR HPV DNA in the cobas assay. The lower rate in the Kerr study may have been influenced by the SurePath media which contains formalin and causes crosslinking of proteins and nucleic acids [34], and/or because more than a third of the samples were from non-OPSCC sites and approximately one half were surgical biopsy samples. Similar to our study, Baldassarri [23] rospectively tested 42 FNA samples collected into PreservCyt media and found only $50 \%$ to be positive in the cobas DNA assay when tested within 1 week of collection, and $90 \%$ of the positives were from patients with OPSCC. The Cervista DNA assays were used by Guo et al. [21] to test 64 FNA samples extracted from alcohol-fixed smears and reported the HPV DNA positivity rate as $75 \%$. Two other HPV DNA testing studies $[17,18]$ used the Hybrid-Capture 2 assay (HC2) to test FNA samples from Surepath or Digene/Qiagen transport media and HPV DNA positivity rates were $58.3 \%$ and $75 \%$ respectively. In our study genotyping with the Aptima HPV 16 18/45 assay, the cobas HPV test and the Cervista HPV 16/18 assay showed strong correlation between the test results and $96.4 \%$ of the positive samples were of HPV genotype 16 . Other studies have reported HPV 16 rates of $88 \%$ using the Cervista HPV 16/18 assay (21) and $92 \%$ (22) and $80 \%$ (23) using the cobas $4800 \mathrm{HPV}$ test.

To determine the accuracy of HPV testing of FNA, comparisons were made to p16 IHC staining of tumors. In our study $77.5 \%(31 / 40)$ of tonsillar tumors stained positive for p16 (Supplementary Table 1) compared to $93.3 \%(28 / 30)$ of BOT tumors ( $\mathrm{p}=0.1)$ (Supplementary Table 2). To our understanding this observation of p16 positivity rate differences according to tumor site has not been reported, and will require a greater number of cases to validate. Overall the FNA samples from patients with p16-positive tumors contained Aptima HPV mRNA in $82.2 \%(51 / 62)$ and cobas HPV DNA in $82.4 \%$ (47/57) (Table 1). HPV positivity rates from patients with p16-positive tumors also showed some differences according to tumor sites, where FNA from patients with tonsillar tumors had higher rates (mRNA 83.9\%, DNA $89.6 \%$ ) than in those with BOT tumors (mRNA 78.6\%, DNA 77.1\%) (Supplementary Tables 1 and 2).
Although two previous studies using the cobas DNA test [23] or the HC2 assay [17] reported perfect correlation between HR HPV DNA positivity in FNA with p16 expression in tumors, other studies $[18,21,22]$ agree with our results, whereby not all of the patients with p16-positive tumors had HPV-positive FNA. This is expected as some squamous cell carcinomas show p16 positivity due to molecular changes, such as mutations, that are unrelated to HPV infection. Our data also shows a few patients with p16-negative tumors having HPV DNA in FNA samples. This could be explained by HPV being present in the background mucosal tissue and/or by HPV DNA contamination across samples. Stringent laboratory techniques were employed to reduce the possibility of contamination in our study.

We observed that FNA samples from 9 patients with p16-positive tumors were negative for both HPV mRNA and DNA suggesting that the FNA samples might have been inadequate. Performing an assay for the presence of $\beta$-actin cellular DNA and examining the Cervista controls for low genomic DNA or a recorded "invalid" result in the cobas HPV DNA test identified 6 FNA samples as inadequate (Table 4). Adequacy of archived and fresh FNA samples for molecular testing has ranged from $44-87 \%$ in previous studies using the internal control of the Cervista HPV DNA assay [19-21]. The presence of HR HPV mRNA and/ or DNA or sufficient $\beta$-actin DNA in fresh FNA samples in our study showed an adequacy rate of $92 \%$. A few patients in our study with adequate amounts of $\beta$-actin DNA in FNA samples and with HPVpositive tumors were negative for HPV in their FNA (patients 8,88 , 38 and 58). A small proportion of OPSCC cases may not be caused by $\mathrm{HPV}$, or the $\beta$-actin test can be positive without HPV-infected cells in the sample. A sensitive and specific point of care test would be ideal to determine adequacy when the FNA is collected.

Previously published studies using commercial HPV assays to diagnose HPV-related HNSCC have tested FNA samples and compared the results to tumor tissue stained for p16 by IHC and tested for HPV by using commercial ISH assays for HPV DNA or HPV16 DNA, ISH assays for HPV RNA [6], HPV DNA PCR [26,35-38] or HPV RNA RTPCR [4]. These studies, including ours, show some lack of specificity of the p16 test. However, this surrogate test is still considered to have the best sensitivity as well as many other favourable attributes to be considered as the test of choice to screen HNSCC [26], and our data confirms this notion.

ISH tests for mRNA rather than DNA performed on tumors are considered to be more relevant for determining the tumorigenic status 
Max C (2017) Performance of Aptima E6/E7 mRNA HPV assays on fine needle aspirates from cervical lymph nodes of patients with metastatic oropharyngeal squamous cell carcinoma

of the SCC $[4,7,8,28]$. Because ISH tests for HPV DNA and mRNA are technically challenging and expensive, we elected to employ a simplified extraction of FFPE tumor tissue to test for the presence of HPV mRNA and DNA using the Aptima and cobas assays, which is a simplified approach for determining the role of HPV in tumor tissue. We did not compare the results of liquid phase HPV testing to ISH testing of the FFPE sections, which could be considered a study weakness. To our knowledge, this is the first report of an extraction procedure compatible for testing for HPV mRNA and DNA with the commercial tests which yielded almost identical results in the 35 cases we were able to examine. This study would have been strengthened if we would have been able to process all 76 of the embedded tissue blocks. Agreement between the p16 results and the HPV assays was $97.1 \%$ and the Aptima HPV mRNA and cobas HPV test showed 100\% agreement on tumor tissue (Table 2). Similarly excellent agreement was shown between the Aptima mRNA assay and the cobas and Cervista DNA tests on FNA samples (Table 3). Showing such a strong correlation between the presence of HPV mRNA in both FNA and tumor tissue in our study suggests that the majority of our cases may have been transcriptionally active with only a few cases lacking a positive mRNA result. This hypothesis could be examined by performing tests for other transformation-related markers such as $\mathrm{pRb}$, oncoproteins, and/ or antibodies against E6 and E7 proteins of HRHPV [39].

Some of these novel findings are supportive for the use of commercial HPV liquid-phase assays to satisfy the desired criteria for testing FNA or fixed or fresh tumor tissue for diagnosing HPVrelated HNSCC. These assays are already incorporated into diagnostic laboratories, are cost-effective with same-day results available and could easily be validated for FNA or tumor tissue. The Aptima HPV E6/E7 mRNA test can be performed on the random access Panther instrument which has been shown to be extremely efficient for other analytes [40]. Although HPV testing of FNA samples shows great promise, more studies including larger numbers of patients with nonOPSCC head and neck tumors will be needed to enable an accurate calculation of specificity.

\section{Role of the funding source /Acknowledgements}

The study was funded by Hologic Inc (San Diego, CA). We would like to thank Kathy Luinstra for performing the $\beta$-actin specimen adequacy assay.

\section{References}

1. Chaturvedi AK, Engels EA, Anderson WF, Gillison ML (2008) Incidence trends for human papillomavirus-related and -unrelated oral squamous cell carcinomas in the United States. J Clin Oncol 26: 612-619. [Crossref]

2. Liggett WH Jr, Sidransky D (1998) Role of the p16 tumor suppressor gene in cancer. $J$ Clin Oncol 16: 1197-1206. [Crossref]

3. Schache AG, Liloglou T, Risk JM, Filia A, Jones TM, et al. (2011) Evaluation of human papilloma virus diagnostic testing in oropharyngeal squamous cell carcinoma: sensitivity, specificity, and prognostic discrimination. Clin Cancer Res 17: 6262-6271. [Crossref]

4. Schlecht NF, Brandwein-Gensler M, Nuovo GJ, Li M, Dunne A, et al. (2011) A comparison of clinically utilized human papillomavirus detection methods in head and neck cancer. Mod Pathol 24: 1295-1305. [Crossref]

5. Moutasim KA, Robinson M, Thavaraj S (2015) Human papillomavirus testing in diagnostic head and neck histopathology. Diagn Histopathol 21: 77-84.

6. Ukpo OC, Flanagan JJ, Ma XJ, Luo Y, Thorstad WL, et al. (2011) High-risk human papillomavirus E6/E7 mRNA detection by a novel in situ hybridization assay strongly correlates with p16 expression and patient outcomes in oropharyngeal squamous cell carcinoma. Am J Surg Pathol 35: 1343-1350. [Crossref]
7. Bishop JA, Ma XJ, Wang H, Luo Y, Illei PB, et al. (2012) Detection of transcriptionally active high risk HPV in patients with head and neck squamous cell carcinoma as visualized by a novel E6/E7 mRNA in situ hybridization method. Am J Surg Pathol 36: 1874-1882. [Crossref]

8. Schache AG, Liloglou T, Risk JM, Jones TM, Ma XJ, et al. (2013) Validation of a novel diagnostic standard in HPV-positive oropharyngeal squamous cell carcinoma. $\mathrm{Br}$ J Cancer 108: 1332-1339. [Crossref]

9. Gillison ML, Koch WM, Capone RB, Spafford M, Westra WH, et al. (2000) Evidence for a causal association between human papillomavirus and a subset of head and neck cancers. J Natl Cancer Inst 92: 709-720. [Crossref]

10. Begum S, Gillison ML, Ansari-Lari MA, Shah K, Westra WH (2003) Detection of human papillomavirus in cervical lymph nodes: a highly effective strategy for localizing site of tumor origin. Clin Cancer Res 9: 6469-6475. [Crossref]

11. Umudum H, Rezanko T, Dag F, Dogruluk T (2005) Human papillomavirus genome detection by in situ hybridization in fine-needle aspirates of metastatic lesions from head and neck squamous cell carcinomas. Cancer Cytopathol 105: 171-177. [Crossref]

12. Begum S, Gillison ML, Nicol TL, Westra WH (2007) Detection of human papillomavirus-16 in fine-needle aspirates to determine tumor origin in patients with metastatic squamous cell carcinoma of the head and neck. Clin Cancer Res 13: 1186 1191. [Crossref]

13. Zhang MQ, El-Mofty SK, Davila RM (2008) Detection of human papillomavirusrelated squamous cell carcinoma cytologically and by in situ hybridization in fineneedle aspiration biopsies of cervical metastasis. Cancer Cytopathol 114: 118-123. [Crossref]

14. Jannapureddy S, Cohen C, Lau S, Beitler JJ, Siddiqui MT (2010) Assessing for primary oropharyngeal or nasopharyngeal squamous cell carcinoma from fine needle aspiration of cervical lymph node metastases. Diagn Cytopathol 38: 795-800. [Crossref]

15. Xu B, Ghossein R, Lane J, Lin O, Katabi N (2016) The utility of p16 immunostaining in fine needle aspiration in p16-positive head and neck squamous cell carcinoma. Hum Pathol 54: 193-200. [Crossref]

16. Barwad A, Sood S, Gupta N, Rajwanshi A, Panda N, et al. (2012) Human papilloma virus associated head and neck cancer: a PCR based study. Diagn Cytopathol 40: 893897. [Crossref]

17. Bishop JA, Maleki Z, Valsamakis A, Ogawa T, Chang X, et al. (2012) Application of the hybrid capture 2 assay to squamous cell carcinomas of the head and neck: a convenient liquid-phase approach for the reliable determination of human papillomavirus status. Cancer Cytopathol 120: 18-25. [Crossref]

18. Smith DF, Maleki Z, Coughlan D, Gooi Z, Akpeng B, et al. (2014) Human papillomavirus status of head and neck cancer as determined in cytologic specimens using the hybrid-capture 2 assay. Oral Oncol 50: 600-604. [Crossref]

19. Solomides CC, Bibbo M, Wang ZX (2012) Assessment of fine needle aspiration specimen adequacy for high-risk HPV detection and genotyping in oropharyngeal squamous cell carcinoma. Acta Cytol 56: 196-198. [Crossref]

20. Lastra RR, Pramick MR, Nakashima MO, Weinstein GS, Montone KT, et al. (2013) Adequacy of fine-needle aspiration specimens for human papillomavirus infection molecular testing in head and neck squamous cell carcinoma. Cytojournal 10: 21 . [Crossref]

21. Guo M, Khanna A, Dhillon J, Patel SJ, Feng J, et al. (2014) Cervista HPV assays for fine-needle aspiration specimens are a valid option for human papillomavirus testing in patients with oropharyngeal carcinoma. Cancer Cytopathol 122: 96-103. [Crossref]

22. Kerr DA, Pitman MB, Sweeney B, Arpin RN, Wilbur DC, et al. (2014) Performance of the Roche cobas 4800 high-risk human papillomavirus test in cytologic preparations of squamous cell carcinoma of the head and neck. Cancer Cytopathol 122: 167-174 [Crossref]

23. Baldassarri R, Aronberg, R, Levi AW, Yarbrough WG, Kowalski D, et al. (2015) Detection and genotype of high-risk human papillomavirus in fine-needle aspirates of patients with metastatic squamous cell carcinoma is helpful in determining tumor origin. Am J Clin. Pathol 143: 694-700. [Crossref]

24. Fonmarty D, Cherriere S, Fleury H, Eimer S, Majoufre-Lefebvre C, et al. (2015) Study of the concordance between p16 immunohistochemistry and HPV-PCR genotyping for the viral diagnosis of oropharyngeal squamous cell carcinoma. Eur Ann Otorhinolaryngol Head Neck Dis 132: 135-139. [Crossref]

25. Venuti A, Paolini F (2012) HPV detection methods in head and neck cancer. Head Neck Pathol 6: S63-S74. [Crossref] 
Max C (2017) Performance of Aptima E6/E7 mRNA HPV assays on fine needle aspirates from cervical lymph nodes of patients with metastatic oropharyngeal squamous cell carcinoma

26. Lewis JS Jr (2012) p16 Immunohistochemistry as a standalone test for risk stratification in oropharyngeal squamous cell carcinoma. Head Neck Pathol 6: S75-S82. [Crossref]

27. Westra WH (2014) Detection of human papillomavirus (HPV) in clinical samples: evolving methods and strategies for the accurate determination of HPV status of head and neck carcinomas. Oral Oncol 50: 771-779. [Crossref]

28. Bishop JA, Lewis JS, Rocco JW, Faquin WC (2015) HPV-related squamous cell carcinoma of the head and neck: an update on testing in routine pathology practice. Semin Diagn Pathol 32: 344-351. [Crossref]

29. Faquin WC (2014) Human papillomavirus (HPV) assays for testing fine-needle aspiration specimens in patients with head and neck squamous cell carcinoma. Cancer Cytopathol 122: 92-95. [Crossref]

30. Dockter J, Schroder A, Hill C, Guzenski L, Monsonego J, et al. (2009) Clinical performance of the APTIMA HPV Assay for the detection of high-risk HPV and highgrade cervical lesions. J Clin Virol 45: S55-S61. [Crossref]

31. Ratnam S, Coutlee F, Fontaine D, Bentley J, Escott N, et al. (2011) Aptima HPV E6/ E7 mRNA test is as sensitive as Hybrid Capture 2 Assay but more specific at detecting cervical precancer and cancer. J Clin Microbiol 49: 557-564. [Crossref]

32. Jobin C, Haskill S, Mayer L, Panja A, Sartor RB (1997) Evidence for altered regulation of I kappa B alpha degradation in human colonic epithelial cells. J Immunol 158: 226234. [Crossref]

33. Groskopf J, Aubin SM, Deras IL, Blase A, Bodrug S, et al. (2006) APTIMA PCA3 molecular urine test: development of a method to aid in the diagnosis of prostate cancer. Clin Chem 52: 1089-1095. [Crossref]
34. Chernesky M, Jang D, Escott N, Gilchrist J, Li J, et al. (2017) Detection of Cervical Precancerous Lesions with Aptima HPV Assays Using SurePath Preservative Fluid Specimens. Papillomavirus Res 3: 155-159. [Crossref]

35. Reimers N, Kasper HU, Weissenborn SJ, Stützer H, Preuss SF, et al. (2007) Combined analysis of HPV-DNA, p16 and EGFR expression to predict prognosis in oropharyngeal cancer. Int J Cancer 120: 1731-1738. [Crossref]

36. Thavaraj S, Stokes A, Guerra E, Bible J, Halligan E, et al. (2011) Evaluation of human papillomavirus testing for squamous cell carcinoma of the tonsil in clinical practice. $J$ Clin Pathol 64: 308-312. [Crossref]

37. Dahlstrand H, Näsman A, Romanitan M, Lindquist D, Ramqvist T, et al. (2008) Human papillomavirus accounts both for increased incidence and better prognosis in tonsillar cancer. Anticancer Res 28: 1133-1138.

38. Weinberger PM, Yu Z, Haffty BG, Kowalski D, Harigopal M, et al. (2004) Prognostic significance of p16 protein levels in oropharyngeal squamous cell cancer. Clin Cancer Res 10: 5684-5691. [Crossref]

39. Baboci L, Holzinger D, Boscolo-Rizzo P, Tirelli G, Spinato R, et al. (2016) Low prevalence of HPV-driven head and neck squamous cell carcinoma in North-East Italy. Papillomavirus Res 2: 133-140. [Crossref]

40. Ratnam S, Jang, D, Gilchrist J, Smieja M, Poirier A, et al. (2014) Workflow and maintenance characteristics of five automated laboratory instruments for the diagnosis of sexually transmitted infections. J Clin Microbiol 52: 2299-2304. [Crossref]

Copyright: $₫ 2017$ Max C. This is an open-access article distributed under the terms of the Creative Commons Attribution License, which permits unrestricted use, distribution, and reproduction in any medium, provided the original author and source are credited. 